\title{
Energy Efficiency Modelling of Residential Air Source Heat Pump Water Heater
}

\author{
Cong-Toan Tran"1, Philippe Rivière ${ }^{2}$, Paul Waide ${ }^{3}$ \\ ${ }^{1}$ MINES ParisTech, PSL Research University, CES - Centre for Energy Efficiency of Systems, 60 Bd St \\ Michel 75006, Paris, France \\ e-mail: cong-toan.tran@mines-paristech.fr \\ ${ }^{2}$ MINES ParisTech, PSL Research University, CES - Centre for Energy Efficiency of Systems, $60 \mathrm{Bd}$ St \\ Michel 75006, Paris, France \\ e-mail: philippe.riviere@mines-paristech.fr \\ ${ }^{3}$ Waide strategic efficiency Ltd, 72 Lairgate, Beverley, United Kingdom \\ e-mail:paul@waide.co.uk
} http://dx.doi.org/10.13044/j.sdewes.2016.04.0007

\begin{abstract}
The heat pump water heater is one of the most energy efficient technologies for heating water for household use. The present work proposes a simplified model of coefficient of performance and examines its predictive capability. The model is based on polynomial functions where the variables are temperatures and the coefficients are derived from the Australian standard test data, using regression technics. The model enables to estimate the coefficient of performance of the same heat pump water heater under other test standards (i.e. US, Japanese, European and Korean standards). The resulting estimations over a heat-up phase and a full test cycle including a draw off pattern are in close agreement with the measured data. Thus the model allows manufacturers to avoid the need to carry out physical tests for some standards and to reduce product cost. The limitations of the methodology proposed are also discussed.
\end{abstract}

\section{KEYWORDS}

Heat pump water heater, Coefficient of performance, Simulation, Test standard.

\section{INTRODUCTION}

\section{Motivation}

The Heat Pump (HP) technology is used to produce heating water for household use. If the grid supply is decarbonised, using HP allows to significantly reduce the carbon dioxide emissions, compared to traditional technologies such as boiler [1]. Coefficient of Performance $(C O P)$ is a key point in product marketing and energy labelling. There are different test standards for HP Water Heaters (HPWHs) in use in different regions of the world. As a result, manufacturers have to undertake a different set of tests for each economy where they sell their products. This adds to product cost and slows the development of the global market. A way to avoid this is to develop a HPWH COP model based on a limited number of tests. Ideally, the model allows local regulators to determine the $C O P$ of products under local test conditions, without conducting additional physical tests.

\footnotetext{
* Corresponding author
} 
The principles of HPWH operation are well understood and some existing models allow HPWH performance to be accurately simulated. Modelling a heat pump is generally divided into two categories: polynomial fits and semi-empirical. In the first category, the correlations are fitted to experimental data as the models presented in [2-4]. The semi empirical approach, for instance the model used in the papers [5-7], is based on thermodynamic evolutions of the working fluid through the components of the heat pump. The model requires data to calibrate its parameters. Some models can be used only for steady state working conditions, such as the model presented in [8], while others allow to study dynamic conditions including the start-up phase and defrosting phase $[9,10]$. The common point of these cited works is that the models are used to predict the COP at an ambient condition which remains constant during the simulation. It is also possible to estimate the average $C O P$ over a season during which the ambient condition changes continuously in time $[11,12]$.

Reviews are presented in [13-15] on simulation techniques for heat pump systems, not only the well-established techniques but also the developing techniques such as the Artificial Neural Network (ANN) technique [16] and the fuzzy theory [17]. It should be noted that all these models are relatively sophisticated, require significant input data [13] and thus are difficult to use in a regulatory environment.

In this context, it is interesting to study the possibility of developing a simplified performance model built from a number of experimental test results and then to examine the predictive capability of the model developed.

\section{HPWH simulation fundamentals}

Determination of the coefficient of performance. Under steady-state working conditions, the instantaneous coefficient of performance is defined as the ratio of the heating power $\dot{Q}$ produced by the HPWH and the electric power $\dot{W}$ :

$$
C O P_{i n s}=\frac{\dot{Q}}{\dot{W}}
$$

In general, $C O P_{i n s}$ depends mainly on the operating conditions, including the ambient temperature and the water temperature. During a standard performance test, the ambient temperature is set to be constant but the tank temperature varies. In this situation, the coefficient of performance is defined by integration over the test duration:

$$
C O P_{i n t}=\frac{\int_{t_{i}}^{t_{f}} \dot{Q} d t}{\int_{t_{i}}^{t_{f}} \dot{W} d t}
$$

where the subscripts int, $i$ and $f$ refer to integrated, initial moment and final moment respectively.

If the heat-up phase without a draw off cycle is considered in isolation, the heating power can be calculated from the tank temperature variation as follows:

$$
\dot{Q}=m c_{p} \dot{T}_{t}
$$


where:

- $m$ is the water mass contained in the tank;

- $c_{p}$ is the specific heat capacity of the water;

- $T_{t}$ is the tank water temperature ( $\dot{T}_{t}$ is then derivative of temperature as function of time).

In addition, the principal variable can be changed from time to the tank water temperature as follows:

$$
C O P_{i n t}=\frac{\int_{T_{i}}^{T_{f}} m c_{p} d T_{t}}{\int_{T_{i}}^{T_{f}} \frac{m c_{p} d T_{t}}{C O P_{i n s}\left(T_{t}\right)}} \approx \frac{\int_{T_{i}}^{T_{f}} d T_{t}}{\int_{T_{i}}^{T_{f}} \frac{d T_{t}}{C O P_{i n s}\left(T_{t}\right)}}
$$

because $m$ and $c_{p}$ are practically constant. Eq. (4) allows the $C O P_{\text {int }}$ to be calculated if the variation of $C O P_{\text {ins }}$ as a function of $T_{t}$ is known. The next section presents some correlation-based models of $C O P_{i n s}$ as a function of $T_{t}$, drawn from the scientific literature.

Existing correlation models. According to [18], for an air cooled HPWH, the instantaneous performance can be expressed by:

$$
C O P_{\text {ins }}=\left[a_{1}+a_{2}\left(T_{t}-T_{d}\right)\right]\left[1-a_{3} \frac{T_{d}-T_{w}}{T_{d}-T_{\text {dew }}}\right]
$$

where $a_{1}, a_{2}, a_{3}$ are constants; and the subscripts $d, w$ and $d e w$ refer to dry bulb, wet bulb and dew point of the surrounding air temperature, respectively. This correlation model was validated using experimental data from two HPWHs: one with a wrap-around condenser coil and the other with an external condenser. The tests were carried out under different ambient conditions without a draw-off cycle. Compared to the measured values, the correlation model gave an average error of $4 \%$ with a maximum error of about $15 \%$.

During the development of the Australian/New Zealand Standard (AS/NZS) [19], a number of alternative correlation functions, including the model presented above, were investigated from which the following model was selected:

$$
C O P_{i n s}=c_{0}+c_{1}\left(T_{t}-T_{d}\right)+c_{2}\left(T_{t}-T_{d}\right)^{2}+c_{3}\left(T_{w}-T_{d e w}\right)
$$

In another analysis of an air-cooled HPWH, known as the EnergyPlus simulation [20], the following correlation is proposed:

$$
\mathrm{COP}_{\text {ins }}=c_{1}+c_{2} T_{a}+c_{3} T_{a}^{2}+c_{4} T_{t}+c_{5} T_{t}^{2}+c_{6} T_{a} T_{t}
$$

where the $c$ coefficients are constants, and $T_{a}$ is either the dry bulb temperature or the wet bulb temperature of the ambient air.

It should be noted that all these correlations were developed to predict the HPWH performance for the whole range of operating conditions. For this reason, they require much experimental data to determine correctly the coefficients. In addition, they were 
only tested in the heat-up phase, their predictive capability is then not known during a whole cycle including both heat-up and draw-off phases.

Objective of the current study. The main objective of the current study is to propose a methodology of simulation which can be used for both a heat-up phase considered in isolation and a whole working cycle including draw-off phases. The model will be based on polynomial functions where the variables are water and air temperatures and the regression coefficients are derived from a very limited experimental data. In particular, we will use the AS/NZS standard test data because, among the existing standards, the AS/NZS standard requires the greatest number of different test conditions during the heat-up phase. The model estimates the COP of the same HPWH under other test standards (i.e. US, Japanese, European and Korean standards), and the simulation results will be compared to measured values.

Specifically, the accuracy of the AS/NZS model of $C O P$, which is the last developed instantaneous $C O P$ model, will be tested against a HPWH data. This model contains 4 variables of temperature. It is worth noting that the air temperatures $\left(T_{d}, T_{w}\right.$ and $\left.T_{d e w}\right)$ are generally correlated in the test standards.

Figure 1 shows dry bulb and wet bulb temperatures collected from different standards, the coefficient of determination $R^{2}$ is equal to 0.98 . Therefore including all 3 air temperatures in the correlation model presents a degree of redundancy and is therefore probably inappropriate. For this reason, we propose to test a three-variable model based on $T_{d}$ and $T_{w}$ and a two-variable based only on $T_{w}$. In summary, the current study investigates the following correlation models:

$$
\begin{array}{cc}
\begin{array}{c}
\text { 4-variable } \\
\text { model } \\
\text { 3-variable } \\
\text { model } \\
\text { 2-variable } \\
\text { model }
\end{array} & C O P_{i n s}=c_{0}+c_{1}\left(T_{t}-T_{d}\right)+c_{2}\left(T_{t}-T_{d}\right)^{2}+c_{3}\left(T_{w}-T_{\text {dew }}\right) \\
& C O P_{\text {ins }}=a_{0}+a_{1} T_{d}+a_{2} T_{w}+a_{3} T_{t} \\
C O P_{i n s} & =b_{0}+b_{1} T_{w}+b_{2} T_{t}
\end{array}
$$

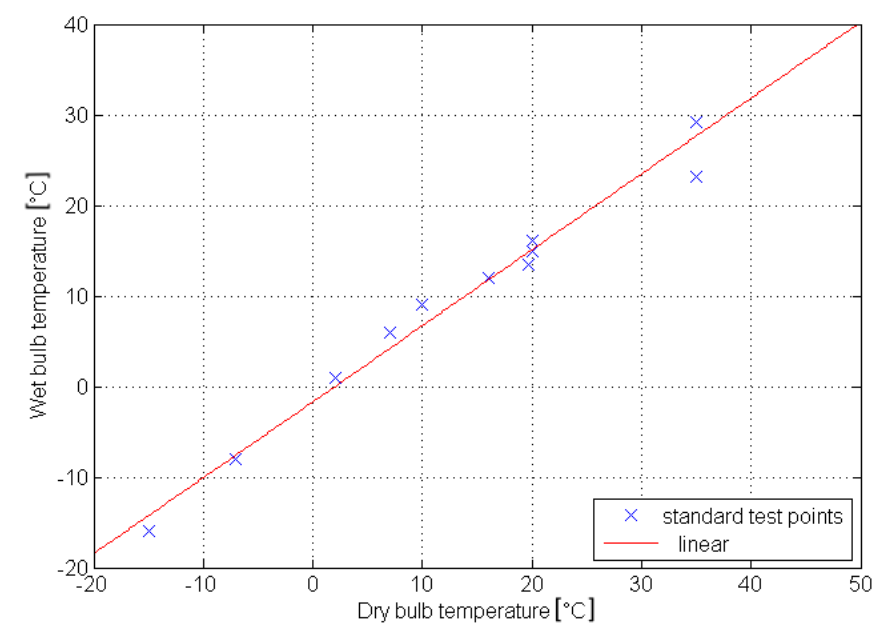

Figure 1. Coincident wet bulb and dry bulb temperatures of the different test standards, including Australian/New Zealand, US, Japanese, European and Korean standards [19, 21-24]

The coefficients can be determined by regression using physical test data. While the air temperatures are obtained from measurements made of the ambient air, the most 
appropriate data used to define the water temperature $T_{t}$ varies with the HP system technology. In general, $T_{t}$ should be the average water temperature in the condenser. In the case of separate HPWHs that have a circulation pump between the tank and the HP, $T_{t}$ is a function of the temperature at the inlet and outlet of the condenser. For integral condenser HPWHs, the definition of the tank water temperature should be based on the average water temperature over the depth of the condenser coil positioned in the tank or wrapped around the tank. Due to the difficulty of applying this definition in real life, an alternative way is to consider $T_{t}$ as the tank water temperature averaged over the whole depth of the tank. In principle this could introduce significant error if the temperature at the condenser inlet significantly differs from the water tank temperature (for separate tank-HP systems) or if the tank is stratified (for integral condenser HPs).

\section{DEVELOPMENT OF A MODEL APPLIED TO HEAT-UP PHASE AND STEADY STATE TESTS}

\section{Methodology}

This section illustrates how a HPWH COP model can be developed and investigates the precision of the models derived.

Figure 2 summarises the main modelling steps, which are subsequently explained in the text.

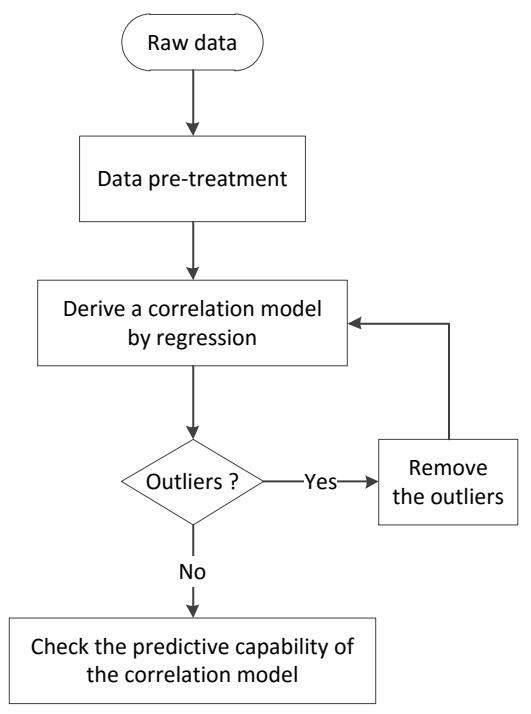

Figure 2. Methodology for modelling HPWH energy performance

Data pre-treatment. First, the raw data needs to be pre-treated. When the data is recorded at a short interval of time, a high level of statistical noise may be observed. Given this, it is better to average the measured data over an appropriate period of time during which the water temperature variation is significant, especially when compared to the measurement uncertainty. In this paper, two levels of temperature variation are studied: $1 \mathrm{~K}$ and $5 \mathrm{~K}$.

Correlation model determination. The least squares method is used to determine the parameters of the three correlation models presented in eq. (8-10).

Outliers. An outlier is defined as an observation that is separated in a particular way from the rest of the data set. In a heating-up phase test, there are generally outliers at the 
beginning and at the end of the test. The outliers should be removed from the data because they can significantly affect the parameters derived for the correlation model. One effective way to find outliers is via residual analysis. In this analysis, a criterion of a "studentised residual" of greater than 3 is used to define an outlier.

Once the outliers have been excluded, a regression model can then be refitted to the data. It is for this reason that an iterative loop is required to repeat the regression until there are no outliers left.

Validation of the correlation model. In order to test the validity of the correlation model experimental data of another test is used to check the predictive capability of the correlation model obtained. Specifically, the estimated $C O P_{\text {ins }}$ derived from the correlation model is compared to the measured values. Finally, the $C O P_{\text {int }}$ over the entire test is determined using eq. (4). The predictive capability of the model is quantified via the error of the model, which is defined as:

$$
\varepsilon=\frac{C O P_{\text {int }}}{C O P_{\text {int }}^{\text {measured }}}-1
$$

\section{Case study}

Description. The machine tested in this study is an air source heat pump water heater. It is monobloc type and uses the basic refrigeration cycle, as shown in Figure 3. The water heater is connected, via hydraulic pipes, to a storage tank. The tank volume is not directly measured, but taken from the technical documentation of the tank. Sensors are installed according to the AS/NZS standard [19]. In particular, water temperatures and flowrate are measured, with sensor uncertainties of $1 \mathrm{~K}$ and $2 \%$, respectively. The electric consumption of the HPWH is also measured (sensor uncertainty of $2 \%$ ), allowing to calculate the $C O P$ of the system.

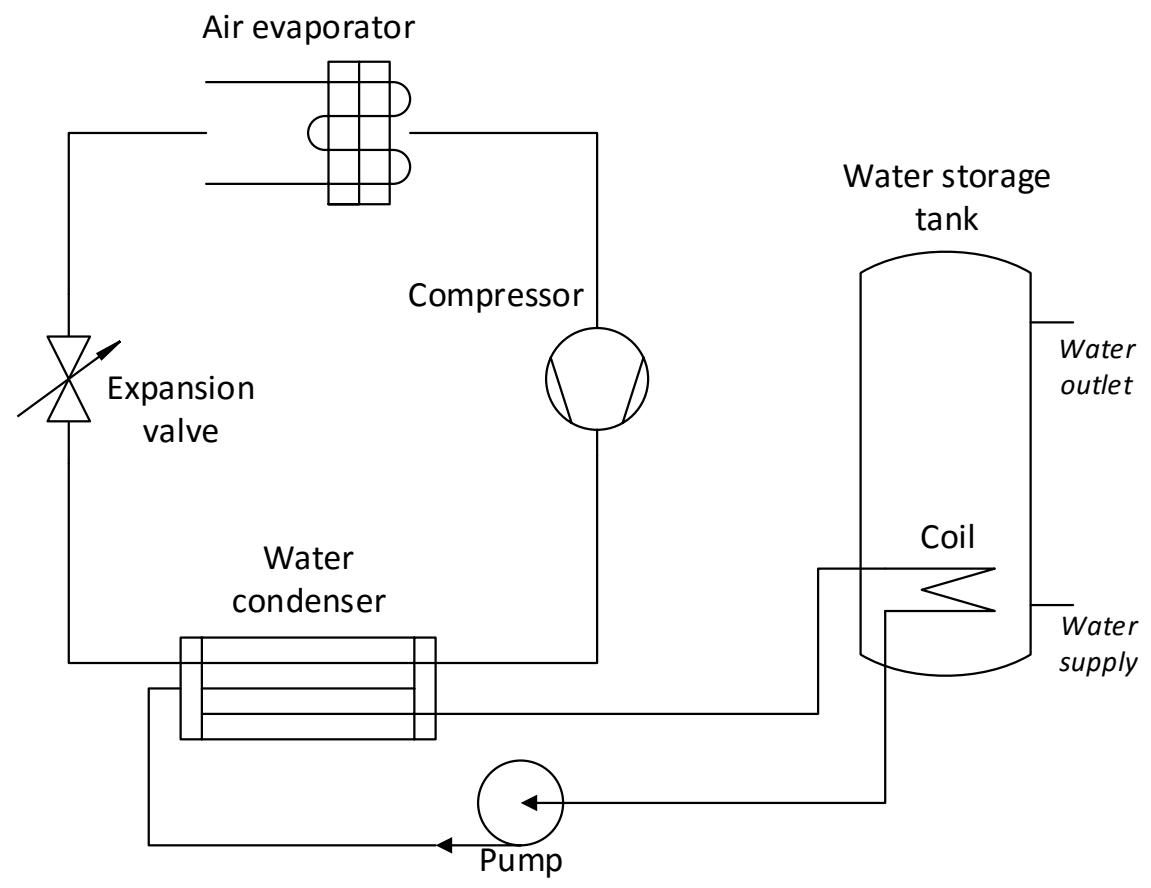

Figure 3. Scheme of the tested HPWH 
Among existing international performance test standards, the AS/NZS standard [19] is the standard that requires the greatest number of different test conditions during the heat-up phase (Table 1). So, in principle a correlation model fitted to the AS/NZS test data could help in predicting heat-up phase performance of other international test standards. For this reason, regression models are derived from a set of four AS/NZS standard tests applied to a HPWH, according to the methodology proposed in Figure 2.

Table 1. Summary of AS/NZS standard test data

\begin{tabular}{ccccc}
\hline \multirow{2}{*}{$\begin{array}{c}\text { Test } \\
\text { number }\end{array}$} & \multicolumn{2}{c}{ Air temperature } & \multicolumn{2}{c}{ Average water temperature } \\
\cline { 2 - 5 } & Dry bulb & Wet bulb & At the beginning of test & At the end of test \\
\hline 1 & 10 & 9 & 9.5 & 58.4 \\
2 & 20 & 16 & 14.6 & 57.4 \\
3 & 35 & 23 & 24.4 & 54.8 \\
4 & 35 & 29 & 24.3 & 54.2 \\
\hline
\end{tabular}

The predictive capability of the models obtained is then verified using test data for the same HPWH measured under the following standards: USA [21], Europe [22] and Japan [23]. The assessment only considers and applies to the heat-up phase without drawoff. The predictive capability of the correlation models are also compared to three sets of test data measured under the Korean Standard [24]. These tests are performed under steady state conditions where the water is continuously drawn off with a constant water flow rate. Table 2 summarises the operational conditions applied in the different test standards.

Table 2. Summary of test data for various test standards applied to the HPWH (NA = not available)

\begin{tabular}{cccccccc}
\hline & \multicolumn{6}{c}{ Outdoor (air) } & \multicolumn{5}{c}{ Indoor (water) } \\
\cline { 2 - 6 } Test & $\begin{array}{c}\text { Dry } \\
\text { bulb } \\
{\left[{ }^{\circ} \mathrm{C}\right]}\end{array}$ & $\begin{array}{c}\text { Wet } \\
\text { bulb } \\
{\left[{ }^{\circ} \mathrm{C}\right]}\end{array}$ & $\begin{array}{c}\text { Water in } \\
{\left[{ }^{\circ} \mathrm{C}\right]}\end{array}$ & $\begin{array}{c}\text { Water } \\
\text { out } \\
{\left[{ }^{\circ} \mathrm{C}\right]}\end{array}$ & $\begin{array}{c}\text { Flow } \\
\text { rate } \\
{[1 / \mathrm{min}]}\end{array}$ & $\begin{array}{c}\text { Water tank } \\
T_{t}\left[{ }^{\circ} \mathrm{C}\right]\end{array}$ & $\begin{array}{c}\text { Operational } \\
\text { phase }\end{array}$ \\
\hline USA & 19.6 & 13.6 & NA & NA & 0 & $\begin{array}{c}\text { Ranging } \\
14-56\end{array}$ & Heating up \\
& & & & & & Ranging & Heating up \\
Europe & 20 & 15 & NA & NA & 0 & $10-56$ & \\
& & & & & & Ranging & Heating up \\
Japan & 15.9 & 12.1 & NA & NA & 0 & $17-57$ & Steady state \\
Korea T1 & 7.0 & 6.0 & 15.1 & 50 & 3.4 & 49.7 & Steady state \\
Korea T2 & 2.0 & 1.0 & 41.1 & 45 & 22.0 & 43.9 & Steady state \\
Korea T3 & 7.0 & 6.0 & 40.1 & 45 & 22.0 & 43.8 & St. \\
\hline
\end{tabular}

Predictive capability of the model developed. As an example for the regression step, Figure 4 shows the regression model of three variables developed from the data of AS/NZS tests. The model gives satisfactory regression $R^{2}$ coefficients of $90 \%$. One can observe that the outliers are at the beginning and at the end of each test. 


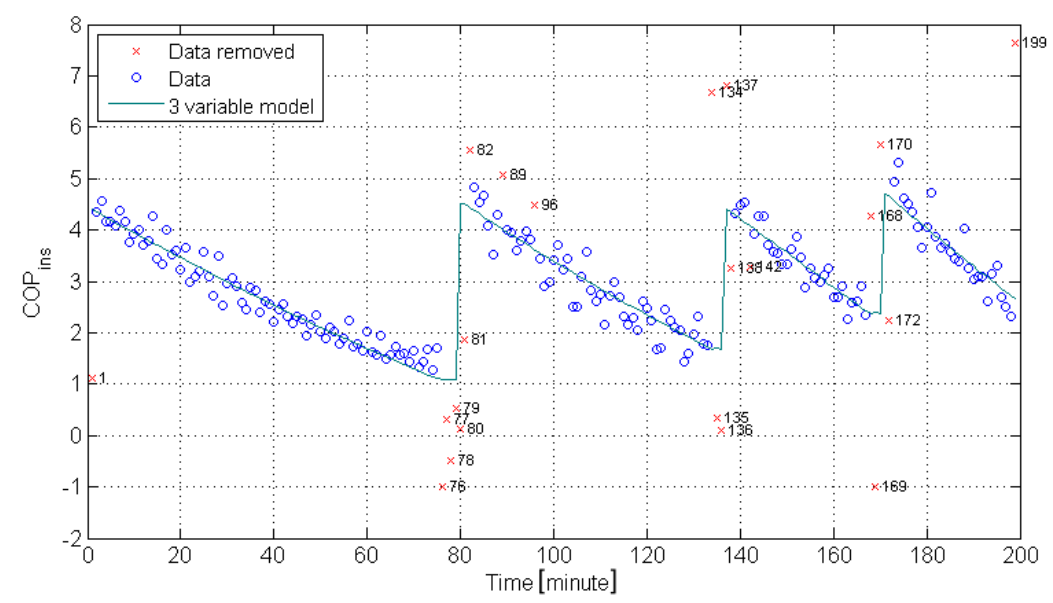

Figure 4. $C O P_{\text {ins }}$ correlation models derived from the four AS/NZS standard tests

Figure 5 shows the correlation models from US standard test, compared to the measured data, where the correlation models are built from 1 Kelvin interval data. The $C O P_{\text {ins }}$ values predicted by the models are relatively close to the measured values.

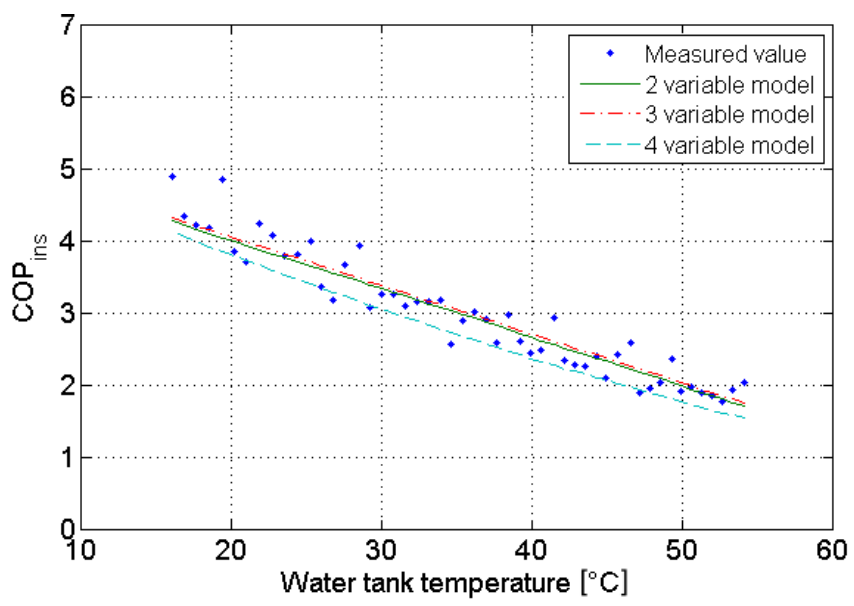

Figure 5. $C O P_{\text {ins }}$ predictive from the correlation models compared to $C O P_{\text {ins }}$ measured

Figure 6 and Figure 7 exhibit graphically the error $\varepsilon$ in the 1-Kelvin interval data and 5-Kelvin interval data models. In both cases, the models obtained have reasonable precision for almost all the test standards, except for the Korean test $n^{\circ} 1$. The main difference between this test and the others relates to the very low inlet water temperature when compared to the water tank temperature. As discussed in part "HPWH simulation fundamentals", this is because the correlation models are likely to be inaccurate when the tank water temperature differs greatly from the condenser water temperature.

Except for the Korean test $\mathrm{n}^{\circ} 1$, the two-variable and three-variable models have a precision better than 5\%. In almost all cases, the four-variable model produces relatively large errors. This may lead to a conclusion that the two-variable and three-variable models are the most appropriate models to be used. Yet the models are all derived from the AS/NZS tests where the air temperatures (dry bulb and wet bulb) are highly correlated. In this case models using both dry and dew point air temperatures may be less accurate as they use redundant data. However, in principle the situation could be reversed in the case of uncorrelated temperature data. In general then, the four-variable model, which is derived from thermodynamic concepts, may give better results. 
The models based on 1 Kelvin interval are not always better than those based on 5 Kelvin interval. Indeed, they are better in the Korean test $\mathrm{n}^{\circ} 3$ (errors of about $1 \%$ against $5 \%$ in the case of the model based on 5 Kelvin interval). However, they are worse in the Japanese test in the case of the 4 variable model.

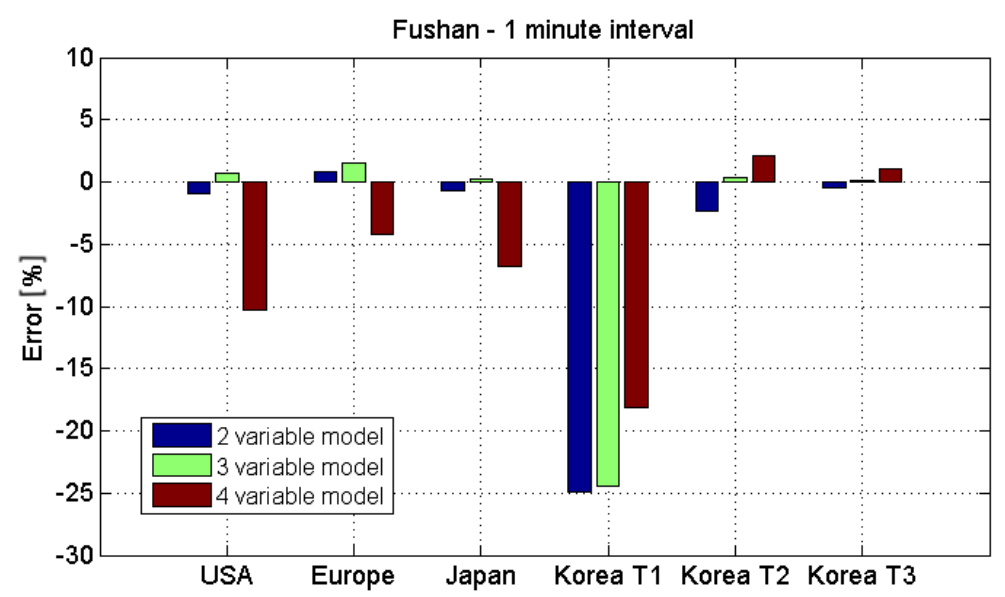

Figure 6. Error in $C O P_{\text {int }}$ predicted by the correlation models derived from 1-Kelvin interval data compared to experimental measurements

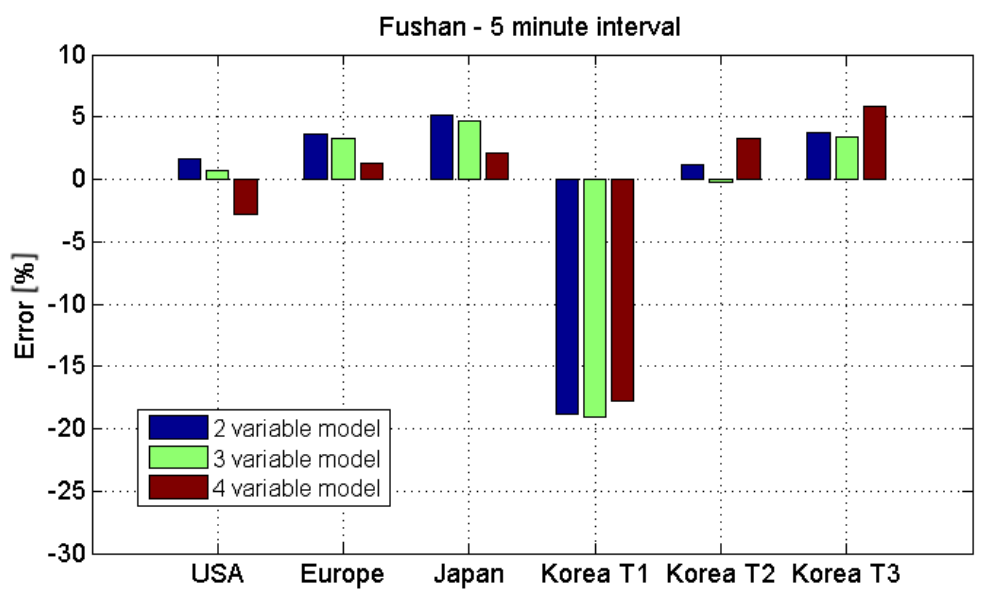

Figure 7. Error in $C O P_{\text {int }}$ predicted by the correlation models derived from 5- Kelvin interval data compared to experimental measurements

\section{DEVELOPMENT OF A MODEL APPLIED OVER A FULL TEST CYCLE INCLUDING A PATTERN OF DRAW-OFFS}

\section{Methodology for modelling performance over a full test}

This section investigates the feasibility of applying the same approach to model a full test that includes a draw-off pattern. In order to do so, the following issues need to be addressed:

- Tank heat losses to the environment; while, tank heat losses can be neglected when compared to the heating capacity of the HPWH during a heat-up phase, they need to be accounted for over a longer time period during which the heat losses represent a significant part of the energy balance;

- Modelling draw-off cycles requires a time simulation of the tank temperature. Therefore, a COP model depending only on temperature variables is insufficient. 
The HP's heating capacity has to be simulated. This can be done via a supplementary model that gives electricity consumption as a function of temperature variables;

- A control-logic model is also required. It should indicate the start and stop times of the HP when operated under a given standard test cycle.

Figure 8 summarises the methodology put forward to model the HPWH operation over a full test cycle including draw-off periods. The following steps are required:

- First, regression models of COP and electric power are developed, using experimental test data measured under limited operational conditions (in our study the AS/NZS test cycle). It is also necessary to develop a heat loss model, from the analysis of a cooling-down period. In addition, a control logic model needs to be determined by observing the operation of the HP;

- Second, the initial variable values are set in accordance with the specifications of the test standard in question;

- The third step is to model the water temperature over time. For each time step, the water temperature is calculated by considering the heat losses, the draw off flow and the HP heating effect. Then, the operational mode of the HP (on or off) is determined;

- Finally, the simulation results are checked by comparison with the measured values.

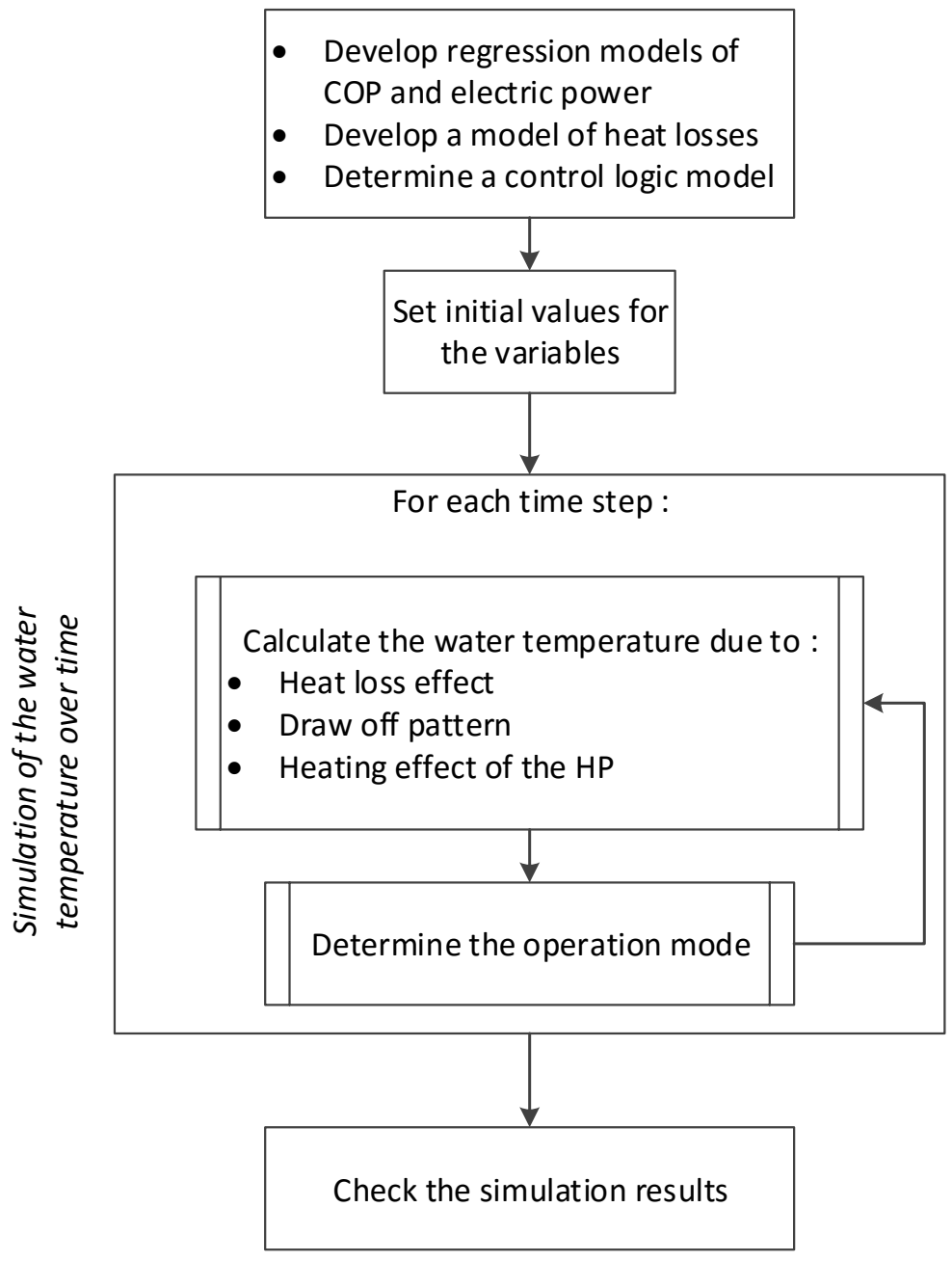

Figure 8. Methodology for modelling HPWH operation over a full test cycle 
Tank heat losses to the environment. Water tank heat losses is generally modelled as follows:

$$
\dot{Q}_{\text {loss }}=U A\left(T_{t}-T_{a m b}\right)
$$

where $T_{a m b}$ is the temperature of the ambient air surrounding the tank and $U A$ is the tank heat loss coefficient. This approach requires a cooling period (i.e. where the HP is stopped and the water tank temperature decreases due to the heat losses), in order to determine the factor $U A$. In addition, the variation of $T_{t}$ must be large enough to allow the UA factor to be accurately determined. For these reasons, the following model is used in place of:

$$
\Delta T_{t}=C_{\text {loss }} \Delta t
$$

where $\Delta T_{t}$ is the variation of $T_{t}$ over a period of time $\Delta t$, and the factor $C_{\text {loss }}$ can be determined from available test data.

Electric power modelling. As for the COP model development, three electric power models are investigated: a linear model of three variables based on the dry bulb and wet bulb air temperatures and the tank water temperature; a linear model of two variables based on the wet bulb air temperatures and the water temperature and finally the model proposed in the AS/NZS standard [19].

$$
\begin{array}{cc}
\text { AS/NZS model } & \dot{W}=c_{0}+c_{1} T_{t}+c_{2} T_{t}^{2}+c_{3} T_{d} \\
\text { 3-variable model } & \dot{W}=a_{0}+a_{1} T_{d}+a_{2} T_{w}+a_{3} T_{t} \\
\text { 2-variable model } & \dot{W}=b_{0}+b_{1} T_{w}+b_{2} T_{t}
\end{array}
$$

Tank temperature model during a draw off cycle. During a draw-off period, the water tank temperature is considered to be homogeneous in the whole tank. This temperature is the equilibrium of the inlet water supply at a temperature $T_{\text {supply }}$ and the water already in the tank at temperature $T_{t}$. Thus, the variation of the tank water temperature over a period of time $\Delta t$ may be calculated as follows:

$$
\Delta T_{t}=\frac{q \Delta t}{V}\left(T_{t}-T_{\text {supply }}\right)
$$

where $q$ is the water flow rate and V is the volume of the tank.

Control logic. A model of the control logic is necessary to simulate the evolution of the tank water temperature over time when a draw-off occurs or when the system is under stand-by operation. The control logic indicates the stop/start times of the HPWH.

\section{Case study}

This methodology is applied to the same HPWH considered in previous parts, in order to develop a model such that regression models are derived using four sets of AS/NZS tests. The heat loss model and control model are determined from the analysis of data taken from a test period where the HPWH is in stand-by operation. The performance of 
the HP is then simulated according to the US test conditions [21] and the predicted results compared to the measured values. Simulation results are subsequently shown.

Tank heat losses to the environment. Data for four cooling phases are extracted and used to calculate $C_{\text {loss }}$ (one of them shown in Figure 9). All four phases show that $C_{\text {loss }} \approx$ $0.031 \mathrm{~K} / \mathrm{min}$. This value is then used in the subsequent full-test simulations.

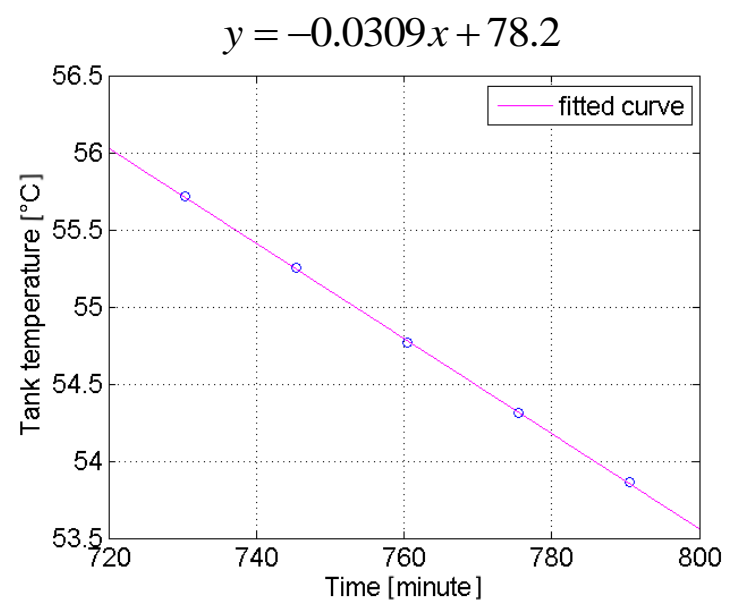

Figure 9. Evolution of the tank water temperature over time for a cooling phase

Electric power modelling. The electric power models obtained are compared to the measured values over the heat-up phase of the US test (Figure 10). The results show that all the models have excellent predictive capability, with errors ranging from $2.2 \%$ for both the linear models down to as lows as $0.9 \%$ for the AS/NZS model. As it produced the best result the AS/NZS model was selected for the rest of the analysis.

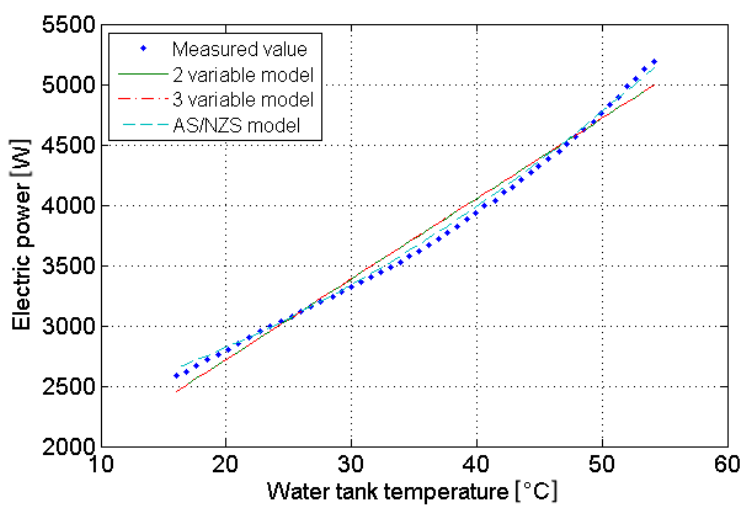

Figure 10. Electric power predictive capability of the correlation models

Control logic. In principle, the electric power drawn by the HP operating in stand-by mode should also be modelled to fully account for the total electric power demand over a complete test. Stand-by power is generally constant and easily measured owing to a stand-by period in the test cycle. In our case, the stand-by power is small enough to be neglected.

Observations of a period of stand-by operation (shown in Figure 11) indicate that the start/stop of the specific HP is controlled so that the water temperature remains within a narrow temperature band around $55^{\circ} \mathrm{C}$. The control logic is likely to be as follows: 
- During a heating phase (when the HP operates) the water temperature increases to an upper set-point temperature $T_{u p}=56.3{ }^{\circ} \mathrm{C}$ above which the HP stops;

- During a cooling phase (when the HP is in stand-by mode) the water temperature decreases until it reaches a lower set-point level $T_{\text {down }}=53.3{ }^{\circ} \mathrm{C}$ under which the HP restarts.

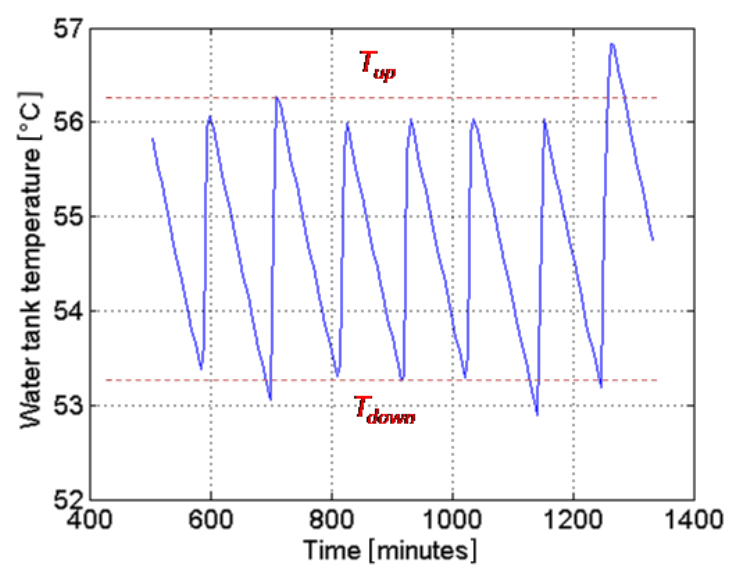

Figure 11. Evolution of the tank water temperature over time during a stand-by period

Simulation results during a whole working cycle. Figure 12 shows the evolution of the water tank temperature for both simulated values and experimentally measured values. The simulation values are generally close to the measured values, especially in the heat-up phase. A delay is observed in the simulated stand-by phases (with or without draw-offs) due to inaccuracy in the control model.

Table 3 compares the simulation results with the measured values. From this it is seen that the heating up time is predicted precisely, with an error as low as $0.6 \%$. The COP error during the heat up phase is small, at about $-1 \%$. The temperature loss, defined as the decrease of the tank water temperature due to the heat loss effect and/or the draw-off pattern, has an error of $1.2 \%$ over the "stand-by and without draw" period. This indicates that the heat loss model is correct. The error of the temperature loss over the "stand-by with draw" period is higher $(-7.5 \%)$, probably due to the stratification effect when a drawoff occurs. The $C O P$ error in this phase is relatively high (-8.2\%), resulting in an error of $-6.7 \%$ for the whole test.

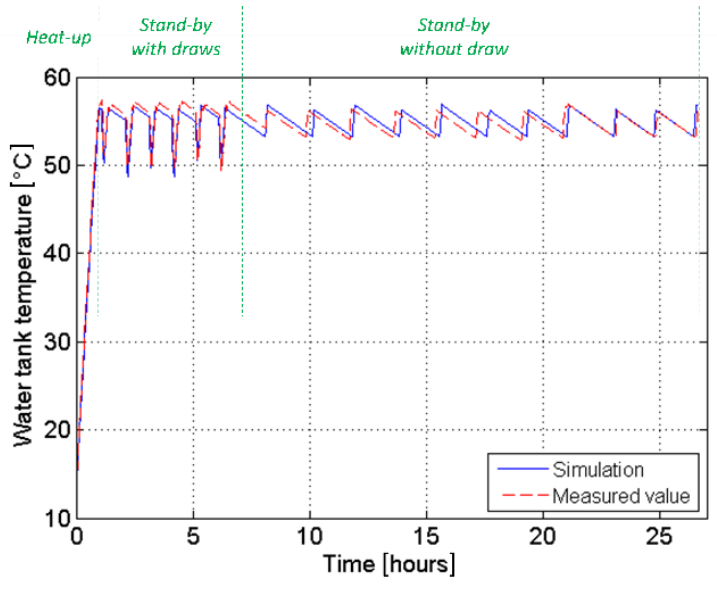

Figure 12. Predictive capability of the full test cycle model developed under the US test standard conditions 
Table 3. Comparison of the model simulation results and the measured values for different operational phases (US test standard conditions)

\begin{tabular}{ccccc}
\hline & \multicolumn{5}{c}{ Simulated } & Measured & Error [\%] \\
\hline Heat up phase & & & & \\
\hline Electric consumption & {$[\mathrm{MJ}]$} & 13.5 & 13.0 & 3.8 \\
Heating up power & {$[\mathrm{MJ}]$} & 36.6 & 35.6 & 2.7 \\
COP & - & 2.7 & 2.7 & -1.0 \\
Heating up time & {$[\mathrm{min}]$} & 58.1 & 57.8 & 0.6 \\
\hline "With draw stand-by" phase & & & & \\
\hline Electric consumption & {$[\mathrm{MJ}]$} & 26.5 & 25.5 & 3.7 \\
Energy of the drawn water & {$[\mathrm{MJ}]$} & 38.0 & 40.0 & -4.8 \\
COP & - & 1.4 & 1.6 & -8.2 \\
Temperature loss & {$[\mathrm{K}]$} & 43.4 & 47.0 & -7.5 \\
\hline "Without draw stand-by" phase & & & & \\
\hline Electric consumption & {$[\mathrm{MJ}]$} & 16.9 & 15.2 & 11.3 \\
Temperature loss & {$[\mathrm{K}]$} & 31.9 & 31.6 & 1.2 \\
\hline Whole test & & & & \\
\hline Electric consumption & {$[\mathrm{MJ}]$} & 56.8 & 53.7 & 5.9 \\
Heating energy & {$[\mathrm{MJ}]$} & 74.7 & 75.6 & -1.3 \\
COP & - & 1.3 & 1.4 & -6.7 \\
\hline
\end{tabular}

\section{LIMITATIONS OF THE PROPOSED METHODOLOGY}

\section{Treatment of back-up electric resistance heaters}

The results presented above show that it is possible to correctly model a HPWH that only uses a heat pump i.e. that does not also use a back-up electric resistance heater. This section aims to evaluate the feasibility of modelling a heat pump system that includes a back-up electric resistance heater. The experimental test data from a second HPWH are analysed for this purpose.

The following three operational modes are considered:

- Periods when only the heat pump is activated;

- Periods when only the electric resistance heater is activated;

- Periods when both the heat pump and electric resistance are used.

In principle it is necessary to develop a performance correlation model for each of these operational modes. A supplementary model of the control system is also required to be able to predict when each of these modes is operational. This model needs to determine the operational mode as a function of the operating conditions i.e. the air and water temperatures.

The control logic of the HPWH in question is as follows:

- At the beginning of the test period both the HP system and electric resistance heater are used;

- When the water tank temperature reaches a specified limit the resistance heater is turned down/off and only the HP works.

Figure 13 shows the water temperature operational-mode limit (i.e. threshold at which the HPWH operates in either the HP-only mode or HP and resistance heater mode) as a function of the dry bulb air temperature, observed from four sets of experimental tests under the AS/NZS standard. From these, the following linear-correlation function (with 
a coefficient of determination $R^{2}=0.99$ ) is derived for the threshold tank water temperature $T_{\text {lim }}$ as a function of the dry bulb air temperature $T_{d}: T_{\text {lim }}=0.47 \times T_{d}+14$

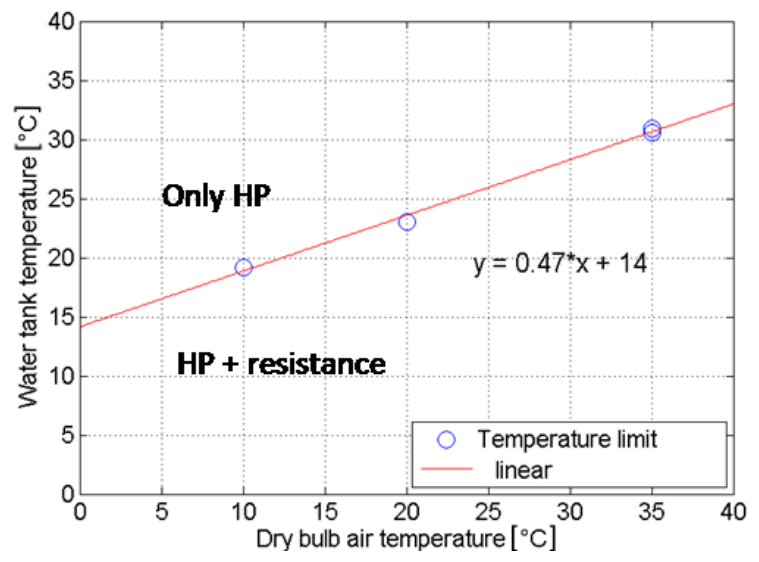

Figure 13. Temperature limit (thresholds) that separate the two operational modes of the HPWH $\mathrm{n}^{\circ} 2$, as observed from four sets of AS/NZS experimental test data

The AS/ZNS test data are also used to develop COP performance correlation models for each operational mode. Three types of models are derived and tested, using two, three and four variables (eq. 8-10). The models obtained are then used to estimate the heat-up phase $C O P$ (i.e. without draw off) that would be expected under the Japanese standard test and the estimates are compared to the corresponding test data (Figure 14). It appears that the control model is not completely satisfactory for the Japanese test standard. Indeed, it underestimates the operational mode temperature limit by about $2 \mathrm{~K}$. This error is probably due to the following factors:

- The control logic is not exactly determined from the tank water temperature, but from temperature sensors which are imperfectly correlated with the tank water temperature e.g. the condenser water temperature, or the refrigerant temperature;

- The control logic may be more complicated than a simple linear model of air and water temperatures.

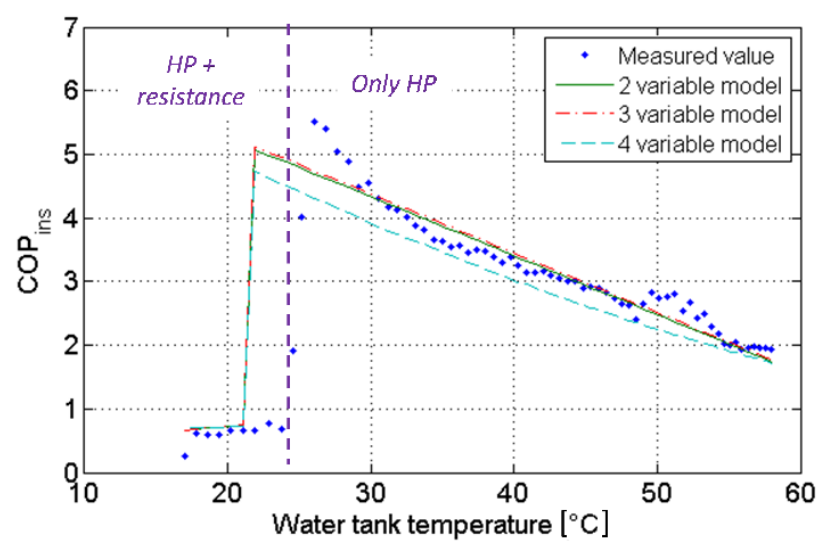

Figure 14. Predictive capability of the correlation models of the HP $n^{\circ} 2$ using an electric resistance

The relatively small error in the control correlation model leads to a significant overestimation of the predicted $C O P$ compared to the measured $C O P$, with the error ranging from +15 to $+22 \%$ depending on the model type (Table 3 ). 
The observed error is explicable due to the following considerations:

- The HP-resistance heater operational mode only occurs for a short period of time, but nonetheless represents about $50 \%$ of the total energy consumption because the design capacity of the resistance heater is much higher than the capacity of the HP;

- Inaccuracy in the control model results in a significant underestimation of the length of the HP-resistance operational mode such that the time the resistance heater is working in practice is twice as high as the model estimate.

Despite this the $C O P$ correlation models are reasonably accurate during the HP mode, especially for the two-variable model.

Table 3. Division of the heat-up phase of the Japanese standard test

\begin{tabular}{|c|c|c|c|c|c|}
\hline \multirow[b]{2}{*}{ Period } & \multirow{2}{*}{$\begin{array}{c}\text { Electric } \\
\text { consumption } \\
\text { measured } \\
{[\mathrm{MJ}]}\end{array}$} & \multirow{2}{*}{$\begin{array}{c}\text { Heating } \\
\text { capacity } \\
\text { measured } \\
{[\mathrm{MJ}]}\end{array}$} & \multicolumn{3}{|c|}{ Error of the $C O P$ predicted [\%] } \\
\hline & & & $\begin{array}{c}\text { Model of } 2 \\
\text { variables }\end{array}$ & $\begin{array}{c}\text { Model of } 3 \\
\text { variables }\end{array}$ & $\begin{array}{c}\text { Model of } 4 \\
\text { variables }\end{array}$ \\
\hline $\begin{array}{c}\mathrm{HP}+ \\
\text { resistance }\end{array}$ & 1.53 & 0.99 & 49.7 & 50.2 & 51.0 \\
\hline Only HP & 1.52 & 4.52 & 0.0 & 1.3 & -8.6 \\
\hline Total & 3.05 & 5.51 & 21.2 & 22.4 & 15.1 \\
\hline
\end{tabular}

\section{Correlating variable issue}

In principle $C O P_{i n s}$ depends on the water temperature surrounding the condenser. Depending on the specific configuration of the HP under consideration, the water temperature surrounding the condenser may be the temperature of the inlet water, the temperature of the outlet water, or even a combination of the two. Due to a lack of appropriate experimental test data, it has been necessary to use the average tank water temperature as the correlating variable for the current study. This is likely to be an appropriate choice when the water being supplied to the condenser is drawn from the water storage tank and the water in the latter is well mixed i.e. is not stratified; and these conditions are more or less satisfied in almost all of the experimental tests investigated in this study. However, it is important to recognise that a model based on average tank water temperature is unlikely to produce reliable results for the following situations:

- When the water supplied to the condenser is drawn directly from the mains water supply (but not from the storage tank), which is true for the Korean tests. In this case, significant error could occur when the inlet water temperature differs appreciably from the tank water temperature, as occurs in Korean test $\mathrm{n}^{\circ} 1$;

- When tank stratification occurs. In the tests studied, this phenomenon is observed in the case of the second HP and only at the beginning of the test (probably due to the activation of the electric resistance heater). The lack of information regarding the exact configuration of the HPWH (i.e. of the geometry of the condenser coil and location of the resistance heater in the tank) and of the inlet and outlet water temperatures does not permit an in-depth study of the impact of this phenomenon on the predictive capability of the model developed.

To avoid these problems, the tank water temperature used in the correlation model should be replaced by a more appropriate variable, depending on the specific configuration of the HPWH. 


\section{Modelling HPWH performance over a full test cycle including a pattern of draw- offs}

Due to the lack of appropriate test data, the heat loss model is reduced to a simpler form which is only appropriate in specific conditions (ambient air temperature constant, little variation of the tank water temperature). In order to generalize the methodology for other conditions, a heat loss model based on eq. (12) would need to be developed.

In addition, the proposed methodology considers that the control logic is the same in all operational modes (heat up, stand-by with or without draw-offs). While this is relatively true for the HPWHs studied, the method may not be appropriate for a HP that uses different control logic dependent on the operational mode. For example, the case when full-load control is used in the heat-up phase and part-load control in the stand-by phase. Additional information on the control system (frequency control, cyclic operation control) used by the specific model of HPWH would then be required to simulate the overall COP. This appears to be a particularly difficult challenge due to the range of differing part load circuitry and control logic used by different manufacturers and it seems unlikely the control logic could be deduced from experimental data. Thus, this limitation could only be overcome if information about the part load circuitry and control logic were to be made available by the manufacturer. In principle, the provision of such information could enable the development of performance models allowing reliable performance prediction over a full test cycle including draw-off patterns.

\section{CONCLUSIONS}

This paper examined the potential to model HPWH energy performance. A simulation methodology applicable to the heat-up phase was presented wherein models of instantaneous $C O P$ were developed using regression techniques. The average COP performance for a standard test was then calculated and compared to the measured values. Three correlation models based on two, three or four-variables were examined.

This method was tested for four sets of AS/NZS standard test data for a HPWH. The performance models obtained were then used to estimate the $C O P$ that would be expected when the same water heaters are tested in accordance with other international standard test procedures and the estimates are compared to experimental data measured for the water heaters tested under these other standards; specifically the heat-up phases of the US, Japanese and European test standards and the steady-state Korean test standard. The simulation results produced are in close agreement with the measured data.

The method was also used to simulate performance over a full test cycle including a draw off pattern. This required an electric power model and a heat loss model to be developed In addition to the $C O P$ model. These models allowed evolution of tank water temperature over time to be determined. The resulting simulations had acceptable errors when compared to the measured values.

It can therefore be concluded that the models developed from the AS/NZS tests give accurate predictions of the HPWH COP during the heat-up phases under other international test standards, and thus could be used to avoid the need to carry out additional physical tests for those standards.

The two-variable and three-variable models give the best results on average, compared to the four-variable model, which is due to the dry bulb and dew point air temperatures used to derive the models being highly correlated.

The limitations of the methodology proposed were also discussed, specifically regarding; the difficulty in modelling a hybrid system (heat pump + electric resistance heater), the choice of regression variables used in the model and the potential to model 
COP performance over a full test cycle including a water draw-off pattern. Recommendations were also given to improve the methodology.

\section{ACKNOWLEDGMENTS}

This work was supported by a Grant (project Heat pump water heaters) from APEC Expert Group on Energy Efficiency and Conservation. The authors wish to thank Dr. George Wilkenfeld and his experts for their very helpful comments on the work. A special thanks is also given to the Korea Testing Laboratory who collected the data that the present study used.

\section{NOMENCLATURE}

$\begin{array}{clc}c_{p} & \text { heat capacity } & {\left[\mathrm{J} / \mathrm{kg}^{\circ} \mathrm{C}\right]} \\ m & \text { water mass } & {[\mathrm{kg}]} \\ \dot{Q} & \text { heating power } & {[\mathrm{W}]} \\ T & \text { temperature } & {\left[{ }^{\circ} \mathrm{C}\right]} \\ \dot{W} & \text { electric power } & {[\mathrm{W}]} \\ \varepsilon & \text { error } & {[\%]} \\ t & \text { time } & {[\mathrm{s}]}\end{array}$

\section{Subscripts}

$\begin{array}{ll}a & \text { air } \\ d & \text { dry-bulb } \\ \text { dew } & \text { dew point } \\ f & \text { final moment } \\ i & \text { initial moment } \\ \text { ins } & \text { instantaneous value } \\ \text { int } & \text { integrated value } \\ t & \text { tank } \\ w & \text { water }\end{array}$

\section{Abbreviations}

AS/NZS Australian/New Zealand Standard

COP Coefficient of Performance

HP Heat Pump

HPWH Heat Pump Water Heater

\section{REFERENCES}

1. Cooper, S. J. G., Dowsett, J., Hammond, G. P., McManus, M. C. and Rogers, J. G., Potential of Demand Side Management to Reduce Carbon Dioxide Emissions Associated with the Operation of Heat Pumps, J. Sustain. Dev. Energy, Water Environ. Syst., Vol. 1, No. 2, pp 94-108, 2013, http://dx.doi.org/10.13044/j.sdewes.2013.01.0007

2. Kinab, E., Marchio, D., Rivière, P. and Zoughaib, A., Reversible Heat Pump Model for Seasonal Performance Optimization, Energy Build., Vol. 42, No. 12, pp 22692280, 2010, http://dx.doi.org/10.1016/j.enbuild.2010.07.007

3. Bourke, G. and Bansal, P., Energy Consumption Modeling of Air Source Electric Heat Pump Water Heaters, Appl. Therm. Eng., Vol. 30, No. 13, pp 1769-1774, 2010, http://dx.doi.org/10.1016/j.applthermaleng.2010.04.008 
4. Tangwe, S., Simon, M. and Meyer, E., Mathematical Modeling and Simulation Application to Visualize the Performance of Retrofit Heat Pump Water Heater Under First Hour Heating Rating, Renew. Energy, Vol. 72, pp 203-211, 2014, http://dx.doi.org/10.1016/j.renene.2014.07.011

5. Byrne, P., Miriel, J. and Lénat, Y., Modelling and Simulation of a Heat Pump for Simultaneous Heating and Cooling, Build. Simul., Vol. 5, No. 3, pp 219-232, 2012, http://dx.doi.org/10.1007/s12273-012-0089-0

6. Song, M., Deng, S. and Xia, L., A semi-empirical Modeling Study on the Defrosting Performance for an Air Source Heat Pump Unit with Local Drainage of Melted Frost from its Three-circuit Outdoor Coil, Appl. Energy, Vol. 136, pp 537-547, 2014, http://dx.doi.org/10.1016/j.apenergy.2014.09.012

7. Yang, L., Yuan, H., Peng, J.-W. and Zhang, C.-L. Performance Modeling of Air Cycle Heat Pump Water Heater in Cold Climate, Renew. Energy, 2015, http://dx.doi.org/10.1016/j.renene.2015.08.055

8. Fardoun, F., Ibrahim, O. and Zoughaib, A., Quasi-Steady State Modeling of an Air Source Heat Pump Water Heater," Energy Procedia, Vol. 6, pp 325-330, 2011, http://dx.doi.org/10.1016/j.egypro.2011.05.037

9. Koury, R. N. N., Faria, R. N., Nunes, R. O., Ismail, K. A. R. and Machado, L., Dynamic Model and Experimental Study of an Air-water Heat Pump for Residential use, Int. J. Refrig., Vol. 36, No. 3, pp 674-688, 2013, http://dx.doi.org/10.1016/j.ijrefrig.2012.11.006

10. Ibrahim, O., Fardoun, F., Younes, R. and Louahlia-Gualous, H., Air Source Heat Pump Water Heater: Dynamic Modeling, Optimal Energy Management and MiniTubes Condensers, Energy, Vol. 64, pp 1102-1116, 2014, http://dx.doi.org/10.1016/j.energy.2013.11.017

11. Madonna, F. and Bazzocchi, F., Annual Performances of Reversible Air-to-water Heat Pumps in Small Residential Buildings, Energy Build., Vol. 65, pp 299-309, 2013, http://dx.doi.org/10.1016/j.enbuild.2013.06.016

12. Dongellini, M., Naldi, C. and Morini, G. L., Seasonal Performance Evaluation of Electric Air-to-water Heat Pump Systems, Appl. Therm. Eng., 2015, http://dx.doi.org/10.1016/j.applthermaleng.2015.03.026

13. Ding, G., Recent Developments in Simulation Techniques for Vapour-compression Refrigeration Systems, Int. J. Refrig., Vol. 30, No. 7, pp 1119-1133, 2007, http://dx.doi.org/10.1016/j.ijrefrig.2007.02.001

14. Swan, L. G. and Ugursal, V. I., Modeling of End-use Energy Consumption in the Residential Sector: A Review of Modeling Techniques, Renew. Sustain. Energy Rev., Vol. 13, No. 8, pp 1819-1835, 2009, http://dx.doi.org/10.1016/j.rser.2008.09.033

15. Qiao, H., Radermacher, R. and Aute, V., A Review for Numerical Simulation of Vapor Compression Systems, in International Refrigeration and Air Conditioning Conference, 2010.

16. Mohanraj, M., Jayaraj, S. and Muraleedharan, C., Applications of Artificial Neural Networks for Refrigeration, Air-conditioning and Heat Pump Systems-A Review, Renew. Sustain. Energy Rev., Vol. 16, No. 2, pp 1340-1358, 2012, http://dx.doi.org/10.1016/j.rser.2011.10.015

17. Underwood, C. P., Fuzzy Multivariable Control of Domestic Heat Pumps, Appl. Therm. Eng., Vol. 90, pp 957-969, 2015, http://dx.doi.org/10.1016/j.applthermaleng.2015.07.068

18. Morrison, G. L., Anderson, T. and Behnia, M., Seasonal Performance Rating of Heat Pump Water Heaters, Sol. Energy, Vol. 76, pp 147-152, 2004, http://dx.doi.org/10.1016/j.solener.2003.08.007

19. Australian / New Zealand Standard 5125.1, Heat Pump Water Heaters Performance Assessment Part 1: Air Source Heat Pump Water Heaters, 2010.

20. EnergyPlus, The Reference to EnergyPlus Calculations, 2012. 
21. U.S. Department of Energy, Code of Federal Regulations (CFR), Title 10, Part 430, Subpart B Appendix E, Uniform Test Method of Measuring the Energy Consumption of Water Heaters, 2012.

22. EN 16147, Heat Pumps with Electrically Driven Compressors - Testing and Requirements for Marking of Domestic Hot Water Units, 2011.

23. JIS C 9220, Residential Heat Pump Water Heaters, 2011.

24. Korean standard, Air Source Heat Pump Water Heater for Residential Buildings (In draft - not yet published), 2013. 